\title{
ODEL - Open and Distance Education and Listening: The Need for Metacognitive Listening Strategies
}

\author{
Dr Jennifer J. Roberts \\ University of South Africa \\ E-mail: buckjj@unisa.ac.za \\ Professor lgnatius G. P. Gous \\ University of South Africa \\ E-mail: gousigp@unisa.ac.za
}

Doi:10.5901/jesr.2014.v4n3p63

\section{Abstract}

Traditionally teaching and learning implied speaking and listening - the master spoke and the learners listened. However, when the sounds died down, the words were gone forever. For that reason people in many cultures developed remarkable oral memory abilities, and learners and performers listened carefully and effectively, thereby managing to remember huge volumes of speech word-for-word. This paper provides a literature review of studies on listening skills, and its impact on academic success and failure. It also gives an overview of metacognitive listening strategies, touching upon how this can benefit students, but especially how educators can and should incorporate it in the way they prepare, present and deliver subject content to their students. The days are long gone where lecturers can merely dump subject knowledge onto students, without including metacognitive learning strategies such as reading and study skills, as well as listening skills. Technological advances are making it possible to make oral presentations as permanent as written ones, and therefore responsible tuition entails teaching in a way that it not only makes it easy for students to listen to presentations, but also teaching them how to listen to what is being taught. Technological advances likewise make it imperative that all educators, whether at contact or at Open Distance Learning (ODL) institutions, become aware and knowledgeable about this, and therefore we have to put Listening back into ODEL.

Keywords: Listening, Listening skills, Metacognition, Distance Education, Teaching

\section{Introduction - Three Statements with a Significant Link}

Hearing is the first sense we become aware of - even before birth in the womb we listen to our mother's voice, her singing and her speech. In life we spend more than half our time listening. When we are dying, sometimes hearing is the last sense that lingers. Even when all other senses have stopped working, we will still hear when people talk to us. Hearing and listening are foundational for being, learning and communicating. It defines our humaneness and our ability to learn.

Technology is a distinctly human capacity. Tools shaped our earliest ancestors' brains and minds, and accelerated us into becoming homo sapiens sapiens - thinking humans. Early technologies made homo better hunters and gatherers, foraging more successfully through their environment and feeding the species' brains with rich nutrients, enabling almost unthinkable growth. Current technologies enable searching for and the storing of vast riches of information, thereby feeding the mind and accelerating learning to unprecedented levels.

Distance Education has enabled expert learning to take place for learners wherever they might be, even when teacher and learner are not within hearing distance of each other.

All of the above is true, but is there a significant link between the three statements? Distance Education is traditionally a silent endeavour because of the physical, temporal and transactional distance between teacher and learner. Therefore, even though hearing and listening might be a crucial capacity in acts of learning, this might not be the case in Distance Education. Technology changed all of this, putting listening squarely back in the picture again. Even though reading and writing will always be the backbone of Distance Education, available technologies such as pod-, penand video-casting led to what is currently being called the "renaissance of the voice".

Breaking the Distance Education "sound barrier" through advanced technology, and thereby giving a voice to 
educators and students again is a significant step. However, will it make a difference in the success rate of Distance Education students? Do educators know how to talk in order for students to listen effectively? Do educators know how to listen to students? Do students know how to listen to lectures and communications? Are students prepared to go into the workplace as proficient listeners? Do we have the meta-skills and meta-awareness to enable effective listening? In short: "Do we know how to LISTEN?"

\section{Methodology}

In order to address this question, we are going to touch on the following important aspects:

- The role of meta-skills in teaching and learning;

- Meta-skill of listening in an ODeL context;

- The act of hearing and the art of listening;

- Hearing and listening in teaching and learning;

- First steps towards implementing metacognitive listening strategies; and

- Concluding by suggesting how listening strategies can be made part and parcel of teaching and learning.

This will be done through a general overview of the literature on listening in education and teaching, with specific emphasis in an ODL environment. This article will serve as the starting point or perimeter scouting basis for the topic of the use and application of the meta-skill of listening in education and teaching.

\section{Meta-skills for Teaching and Learning}

Most of us have heard and agree with the age-old and well-known proverb of Chinese origin: Give a man a fish and you feed him for a day. Teach a man to fish and you feed him for a lifetime. Having heard that, do we listen to this advice when teaching? Often in teaching and learning the focus seems to be on mastering course content. Knowledge expands at such a pace, however, that qualifications have a limited life span before they become outdated. Hence there is the need for students to become life-long learners, in order to keep up to date by learning and re-learning.

Successful life-long learners display certain characteristics, with certain meta-skills part and parcel thereof. Metacognition is the ability to plan, monitor and evaluate self, tasks and strategies in pursuit of meaningful goals (Flavell, 1979,906-911). Strategies crucial for successfully completing learning tasks are listening, reading, writing and study skills.

The reality is that these skills are seldom taught or being taught continuously, with listening being taught the least of all (Coakley \& Wolvin, 1997, Wacker \& Hawkins, 1995, Janusik, 2002, Janusik \& Wolvin, 2002). Listening, for example, is experienced as being so natural that people take it for granted that they are good listeners. When hearing is compromised it receives attention, but listening as a communication skill in general and specifically as a teaching and learning skill is seldom addressed or taught. Reading is taught at primary school level, but after students have mastered the deciphering process, readers are usually left to fend for themselves. Students are expected to study the subject matter and course content, but how they are supposed to do it, is not attended to systematically or even not at all. It is for this reason that students often arrive at college or university as rote learners, as well as poor readers and listeners. In similar vein, good writing seems to be an endangered skill.

Some educators and educational institutions are aware of this. Many colleges and universities have tips for studying, reading, listening and note taking available on their web sites (several websites are mentioned in the references). Study skills courses are available in abundance in books, on the web and in face-to-face classes. Reading and speed reading courses are even beginning to become available as applications on smartphones and tablets. These are positive developments and necessary rectifications, with many students benefiting from attending to them. As addons and loose-standing interventions, however, they actually function on the same level as "giving a man a fish to eat", with students being presented these meta-skills in a stand-alone fashion with the expectation that they will be able to transfer these skills to subjects and apply them to the mastering of specific course content all by themselves. In order to be really effective and to transform students into life-long learners who are able to fend for themselves, the subjectspecific intelligence and skills necessary for mastering the course material should be provided as an integral part of the course content.

Both lecturers and students need to be made aware how to incorporate meta-skills such as listening, reading, writing and studying in teaching and learning, and this article is part of a series of articles on meta-skills in education. 
Focusing on listening, this article provides an introduction to the theory and practice of listening as a meta-skill in the context of Distance Education.

\section{Meta-skill of Listening in an ODeL Theoretical Context}

This article investigates the meta-skill of listening in a Distance Education environment. The theoretical framework for this study is based on the classification of Distance Education into different generations based on technological as well as pedagogical constructs.

Various authors have presented Distance Education generational models with all of them proposing that the $1^{\text {st }}$ generation of Distance Education encompasses all forms of correspondence education, with the defining characteristic being content in printed format. The following table provides an overview of some of these authors (Heydenrych \& Prinsloo, 2010, 8-9):

Table 1. Overview of generations of Distance Education

\begin{tabular}{|l|l|}
\hline \multicolumn{2}{|l|}{ Garrison (1995) [In: Peters, 1998] } \\
\hline $1^{\text {st }}$ & Correspondence - single medium (print) - mass production of content \\
\hline $2^{\text {nd }}$ & Tele-conferencing - audio - communications network - synchronous \\
\hline $3^{\text {rd }}$ & Multi-media, computer-assisted learning and communication - interaction with content \\
\hline Lauzon and Moore (1989) \\
\hline $1^{\text {st }}$ & Correspondence - single medium (print) - mass production of content \\
\hline $2^{\text {nd }}$ & Teleconferencing - audio - communications network - synchronous \\
\hline $3^{\text {rd }}$ & Multi-media and computer-assisted learning - interaction with content \\
\hline $4^{\text {th }}$ & Student control and sharing collective intelligence - Internet/WWW \\
\hline Guglielmo (1998) \\
\hline $1^{\text {st }}$ & Correspondence - single medium (print) - mass production of content \\
\hline $2^{\text {nd }}$ & Multi-media and computer-assisted learning - interaction with content \\
\hline $3^{\text {rd }}$ & Group communication - Internet/WWW communication technologies \\
\hline Taylor (1999 and 2001) \\
\hline $1^{\text {st }}$ & Correspondence - single medium (print) - mass production of content \\
\hline $2^{\text {nd }}$ & Teleconferencing - audio - communications network - synchronous \\
\hline $3^{\text {rd }}$ & Multi-media and computer-assisted learning - interaction with content \\
\hline $4^{\text {th }}$ & Flexible learning via online delivery - communication enhanced online \\
\hline $5^{\text {th }}$ & Intelligent flexible learning - automated content and responses and campus portals \\
\hline Moore and Kearsley (2005) \\
\hline $1^{\text {st }}$ & Correspondence - single medium (print) - mass production of technology - correspondence \\
\hline $2^{\text {nd }}$ & Radio and television broadcasting \\
\hline $3^{\text {rd }}$ & Combined approach - correspondence assisted by broadcasting (open universities) \\
\hline $4^{\text {th }}$ & Telelearning - interactive audio/video conferencing \\
\hline $5^{\text {th }}$ & Online delivery - multimedia interactive content with online communication and support \\
\hline
\end{tabular}

These authors have based their classification primarily on the technologies used in Distance Education, while other authors have proposed Distance Education generations based on pedagogy that defines the learning experiences encapsulated in the learning design.

Anderson \& Dron $(2011,80)$ describe three generations of distance education pedagogy, being cognitivebehaviourist, social constructivist and connectivist.

Table 2: Summary of Distance Education Pedagogies

\begin{tabular}{|c|c|c|c|c|c|c|c|}
\hline $\begin{array}{l}\text { Generation of Distance } \\
\text { Education Pedagogy }\end{array}$ & Technology & $\begin{array}{c}\text { Lear-ning Activi- } \\
\text { ties }\end{array}$ & $\begin{array}{c}\text { Learner } \\
\text { Granulari-ty }\end{array}$ & Content Granulari-ty & Evalua-tion & $\begin{array}{l}\text { Teacher } \\
\text { Role }\end{array}$ & $\begin{array}{c}\text { Scalabili- } \\
\text { ty }\end{array}$ \\
\hline Cognitive- behaviourism & \begin{tabular}{|l} 
Mass media \\
Print \\
TV \\
Radio \\
One-to one \\
communication
\end{tabular} & Read and watch & Individual & \begin{tabular}{|l} 
Fine: \\
Scripted and designed \\
from the ground up
\end{tabular} & Recall & $\begin{array}{l}\text { Content } \\
\text { creator } \\
\text { Sage on } \\
\text { stage }\end{array}$ & High \\
\hline Constructivism & Conferen-cing & Discuss, create and & Group & Medium: & Synthesize: & Discus-sion & Medium \\
\hline
\end{tabular}




\begin{tabular}{|c|c|c|c|c|c|c|c|}
\hline & $\begin{array}{l}\text { (Audio, video and web) } \\
\text { Many-to-many } \\
\text { communication }\end{array}$ & construct & & $\begin{array}{l}\text { Scaffolded and } \\
\text { arranged } \\
\text { Teacher-guided }\end{array}$ & Essays & \begin{tabular}{|l} 
leader \\
Guide on \\
the side
\end{tabular} & \\
\hline Connectivism & \begin{tabular}{|l|} 
Web 2.0 \\
Social networks \\
Aggregation and \\
recommender systems
\end{tabular} & \begin{tabular}{|l|} 
Explore, connect, \\
create and evaluate
\end{tabular} & Network & $\begin{array}{l}\text { Course: } \\
\text { Mainly at object and } \\
\text { course level } \\
\text { Self created }\end{array}$ & $\begin{array}{l}\text { Artefact } \\
\text { creation }\end{array}$ & $\begin{array}{l}\text { Critical } \\
\text { friend } \\
\text { Co-traveller }\end{array}$ & Low \\
\hline
\end{tabular}

http://www.slideshare.net/akor0003/three-generations-of-distance-education-pedagogies

From Table 2 it can be seen that the skill of listening is required in each of the distance education pedagogies from TV, radio and one-to-one communication in the cognitive-behaviourist pedagogy, audio, video and web conferencing in the constructivist pedagogy to Web 2.0 and social connection in the connectivist pedagogy.

For the purpose of this research article, the authors have borrowed from both of these generational classifications. Technology plays a large part in listening in Distance Education. Unlike contact, classroom style content delivery, in Distance Education the method of content delivery is not through a face to face situation where lecturer and students can interact in close proximity with eye to eye contact. Content delivery has to be provided through a technological medium, which according to Table 1 can range from printed to audio to multimedia interactive communication.

Anderson and Dron $(2011,80)$ state "It is clear that whether the learner is at the centre or part of a learning community or learning network, learning effectiveness can be greatly enhanced by applying, at a detailed level, an understanding of how people can learn more effectively: Cognitive, behaviourist, constructivist and connectivist theories each play an important role."

The skill of listening is thus central to all the generations of Distance Education, with possibly the $1^{\text {st }}$ generation in Table 1 above being the exception. Wherever learning takes place in an audio context, whether it is audio cassettes, video conferencing, radio, one way communication, podcasting or Massive Open Online Courses (MOOCS), the metaskill of listening is the key to effective learning in an ODL context.

According to Beall, Gill-Rosier, Tate and Matten $(2008,124)$, effective listeners are usually more successful in academia and educators have known for a long time that listening is an important part of the teaching-learning process. The importance of listening in the education process relates to both face to face as well as distance education. However, it becomes more important in distance education where the learning experience can be a lonely and isolating space. At many higher education institutions, distance learners seem to have the highest risk of dropping out of their studies and according to Peters (1992), the attrition rates can be attributed in part to the isolation experienced by many Distance Education students.

Lee and Chan $(2007,85)$ have suggested that supplementary audio podcasting is a method to reduce the anxiety inherent in Distance Education students and can also promote a sense of inclusivity among students. Moore $(2007,91)$ states that ODL is characterised by the distance that exists between educator, learner and institution, which he calls the transactional distance. He describes transactional as "the space where instructors and learners accomplish the work of learning in an environment that separates actors in both time and geographic distance", and also "the interplay of teachers and learners in environments that have the special characteristic of being spatially separate from one another". This situation creates a cognitive space between educator and learner, "a psychological and communications gap, a space of potential misunderstanding between the inputs of instructor and those of the learner" (Moore, 1997). Lee and Chan $(2007,86)$ state further that this geographical isolation contributes further to the lack of social interactions faced by Distance Education students.

Durbridge (1984) emphasizes the distinct pedagogical advantages of audio over printed matter. She states that "As compared with written text, the spoken word can influence both cognition (adding clarity and meaning) and motivation (by conveying directly a sense of the person creating those words)."

Smaldino, Russell, Heinich and Molenda (2005) note that the use of audio in education presents numerous advantages which include the fact that it is inexpensive and readily available; its ease of production and use; the qualities of repeatability and reproducibility; its ability to stimulate listeners and to provide a verbal message for non-readers and the portability of the medium.

In contiguous teaching, participants can talk in real time, but Distance Education fell silent for many years because of the use of correspondence print (Taylor, 2001), thereby creating a sound barrier.

Gous and Roberts (2013) refer to the use of technology in order to break this sound barrier in Distance Education through the use of a specific educational teaching aid namely the Livescribe Smartpen ${ }^{\odot}$. This device can record audio clips e.g. a mini-lecture which is then transformed into a pdf document which can be sent to all students. The students do not need to be in possession of the smartpen - they simply need access to the pdf file whether it is on the computer, 
tablet, ipad or smartphone.

Lee and Chan (2007) investigated the potential of using audio podcast material to address the anxieties and isolation felt by Distance Education students. In their research they found that students see the podcasts as being beneficial to the affective and cognitive aspects of their learning.

To sum up: Spoken communication is what set homo sapiens sapiens apart from other primates, according to the cognitive archaeologist Steven Mithen (1996). Where people previously had specialised mind modules devoted to specific tasks completed in relative isolation, spoken communication broke down the barriers between modules, and added the ability "to tell" to the existing strategy "to show" when guiding novices to master necessary survival knowledge and skills. It is, in some instances, easier to talk someone to a distant hunting ground than to walk him there, as it were. Therefore teaching has, and always will be a narrative process.

\section{The Act of Hearing and the Art of Listening}

Distance education and ODL are specialised and focused means of communication with the aim to impart knowledge, skills, understanding and attitudes that are necessary to fulfill certain roles and tasks in professions. As has been seen from the previous overview of Distance Education and ODL, the means of communication in these settings are currently varied and rich, including all aspects of communication - reading, writing, speaking, hearing and listening. Listening is foundational to communication and used extensively, but even so is a neglected and often not well understood communication skill. For this reason it should receive more attention as an aspect of teaching and learning.

As foundational aspects of communication, hearing and listening have been researched extensively. Janusik (2002) shared interesting "listening facts" based on verified research studies.

Research carried out since 1930 indicates that we spend more time on listening than on reading, writing and speaking, whether in daily life or in college. According to Imhof \& Weinhard (2004) primary school learners in Germany spend $66 \%$ of their time having to listen in class. Even so, it is also been shown that people are not good at listening, and do not remember much of what they have heard or have been listening to (Janusik, 2002), Stauffer, Frost \& Rybolt, 1983).

Meaning is not transmitted only by words. According to Mehrabian (1981), 55\% of meaning is transmitted nonverbally, $38 \%$ by the tone of voice, and $7 \%$ by the words. Understanding is therefore so much more than mere deciphering - it is a comprehensive interpretive endeavour. There are advantages and disadvantages to this. When listening, people naturally attend to the full spectrum of the what, why and how of the communicated message. This contributes to grasping the richness of the message. It may, however, also cloud understanding in the sense that people might get sidetracked by issues not central to what is being communicated. This is especially true in academic and teaching instances, where communication is supposed to be precise and the focus is on what is being communicated. It is here where listening pedagogy and listening style becomes pertinent, as discussed later in the paper.

People can listen at a rate much faster than the rate they can talk. People on average can talk at about 125 - 175 words per minute, while we can listen at a rate of up to 450 words per minute (Carver, Johnson \& Friedman 1970). The implication of this is that people's minds may begin to wander while listening, and speakers need to be aware of it and compensate for it, using strategies to help keep attention.

There are many barriers to listening. For example, Watson \& Smeltzer (1984) found the most prevalent barriers to listening amongst business students were personal disinterest in the topic, personal and internal distractions such as hunger, headache or preoccupation with something else, and inattentiveness because of daydreaming. In ODL settings where students might sit listening while on their own, many more barriers might come into play, which should be researched.

People may hear well, but listen poorly. Poor listening skills may contribute substantially to the high failure rate of ODL learners (Peters, 1992). From all of the above, it is clear that we hear a lot, but do not listen properly. We need to be trained to listen adequately.

\section{Hearing and Listening in Teaching and Learning}

Traditionally teaching and learning implied speaking and listening - the master spoke and the learners listened. However, when the sounds died down, the words were gone forever. For that reason people in many cultures developed remarkable oral memory abilities, and learners and performers listened carefully and effectively, thereby managing to remember huge volumes of speech word-for-word. However, these remembered residues only existed in a few minds, 
and it took a lot of time and many more minds to duplicate these memories. Information became too voluminous to reside in a few trained minds, therefore more permanent representation and storage were needed. Marks on walls and stones eventually developed into writing systems, and today vast amounts of knowledge is stored in billions of books and recently electronic giga-bytes.

Even though knowledge is primarily stored in writing and therefore to be accessed through vision, oral teaching is still the preferred way of instruction. Learning in families starts off through verbal interactions, and teaching in school and thereafter still leans towards lectures or variations thereof. Learners are verbally and orally instructed on how to master written information.

Good students listen well. Conaway (1982) gave a first year students' class of over 400 a listening test at the beginning of their first semester. After their first year of studies, $49 \%$ of students scoring low on the listening test were on academic probation, while only $4.42 \%$ of those scoring high on the listening test were on academic probation. Conversely, $68.5 \%$ of those scoring high on the listening test were considered for Honors Students after the first year, while only $4.17 \%$ of those scoring low attained the same success.

The problem is that learners are not taught how to listen. Research started by Nichols in 1948 and continuing to this day underscored the fact that listening is a critical factor in academic success, but it also showed that people are actually very poor listeners. He found, amongst other things, that college students remember $25 \%$ or less from what they hear, and women are better listeners than men.

Students do not necessarily know how to listen well, and are not always aware that listening is an activity they have control over. Imhoff (1998) reports that students find it easy to criticise the speaker, but find it difficult to evaluate and criticise what the speaker has said. This, however, improved after training in metacognitive listening strategies such as asking pre-questions, interest management and elaboration strategies.

Does all of this matter in Distance Education and ODL contexts? With technology bringing talking and therefore listening back into Distance Education and ODL, listening skills are very topical, and poor listening skills may be a contributing factor in the high dropout and failure rate of ODL learners. Furthermore, listening skills are a precursor to reading, because reading is related to listening in the sense that reading is "silent listening" with many overlapping or related principles and strategies.

It is clear that listening is central to teaching and learning. Educators therefore can and should incorporate metacognitive listening strategies in the way they prepare, present and deliver their subject content to their students. The days are long gone where lecturers can merely dump subject knowledge onto their students, without including metacognitive learning strategies such as reading and study skills, as well as listening skills. Technological advances are making it possible to make oral presentations as permanent as written ones, and therefore responsible teaching entails teaching in a manner that it not only makes it easy for students to listen to presentations, but also to teach them how to listen to what is being taught. Technological advances likewise make it imperative that all educators, whether at contact or at ODL institutions, become aware and knowledgeable about this, and therefore we have to put Listening back into $\mathrm{ODL}$.

\section{Metacognitive Listening Strategies - First Steps}

In order to ensure that listening skills do not become a one-day-fish intervention, they should form part of a comprehensive approach based on sound theory and leading to feasible strategies. A comprehensive approach should at least take into account listening styles and their relations to self-knowledge, with resulting strategies.

Contrary to popular belief, there is not only one way in which people listen. There are different listening styles and habits, each with its own characteristics, strengths and blind spots. From this it follows naturally that some listening styles are more appropriate to a certain kind of task than others, and learners should be knowledgeable about this in order to become effective students.

To be knowledgeable about listening preferences does not mean that people are convicted of and sentenced for life to a singular way of listening. Knowing and understanding listening styles, habits and preferences empower people, in the sense that they know and understand the way they listen, but that they are also aware of how other people listen. In doing so, it enables them to widen their own listening repertoire and empowers them to choose listening styles appropriate to the task at hand.

Metacognition is about planning, monitoring and evaluating teaching and learning, by knowing and controlling oneself, the task one has to complete, and the strategies best suited to do so (Flavel, 1979, Hardiman, 2012). Learners constantly face a variety of learning tasks. To be a successful learner, one has to assess and understand the task and 
what constitutes successful completion of the tasks. Some tasks might be to learn basic facts, others might be to understand principles, others may be to learn how to co-operate, others might be to create something new, and many more. Different tasks require different strategies or sets of strategies.

Strategies chosen are influenced by the self, amongst other things. There are many assessments, test and measurements available to assess personality style. The authors of this article, Roberts and Gous (2013) developed an AwE (Awareness Exercise) called Prism Break, based on Myers-Briggs, but geared towards ease of use and understandability (Roberts and Gous, 2013). Based on a questionnaire, learners are assessed and assigned a colour green, yellow, blue or orange. The colours as such do not carry any significance or meaning but are merely a metaphor for personality styles and is based on the Myers-Briggs assessments. So-called green learners are thinkers and look for facts. So-called yellow learners are more rule-bound, and value predictability and order. The blue learners are peopleorientated and caring, and the orange learners are focused on action and the big picture. Each person is not only one colour, but displays a combination or spectrum of colours and therefore preferences and habits. People have a preference, but are able to choose and use less-preferred predispositions, modes of thinking, actions and feelings.

Once again these colours are depicting preferred ways of being and doing and therefore also choice of strategies. The ultimate idea is that people should be aware of their own preferences and habits, but also be aware of other people's preferences and habits, and then choose to act in ways suitable, relevant and appropriate to the task at hand.

Listening is an often-used strategy, also displaying characteristic styles, habits and preferences. Much research has been carried out about listening styles. One that has been used widely and even made it into the popular domain, is the Listening Styles Profile (LSP-16), developed by Watson, Barker and Weaver (1995). It is a sixteen-item inventory to assess four distinct approaches to receive information: people-, action-, content-, and time-oriented styles.

Bodie, Worthington and Gearhart (2013) evaluated the LSP-16, pointing to problems with reliability and an unvalidated factor structure. They revised it and came up with the LSP-R assessment scale and suggested the following four listening styles: Critical, task-oriented, relational and analytical. Critical listening prefers logic and factual content. Task-oriented listening prefers structure and dislikes disorganised utterances. Relational listening concerns understanding emotions and connecting with others. Analytical listening is interested in the big picture and considers all sides of an issue.

Comparing the two assessments (Prism Break and LSP-R), they seem to point in the same direction. The green personality style and the critical listening style portray similar characteristics, as do yellow and task-orientated listening, blue and the relational listening and orange and analytical listening.

For example, if a "blue" student with a relational listening style has to master basic mathematical facts, he/she has to learn to suspend the preference to listen to emotions and the way the lecturer speaks, and rather activate and foreground his critical listening techniques, thereby listening for gathering facts. Another student, a "yellow" one with a task-orientated listening style and listening to a lecture on creativity, will have to suspend the preference for order, structure and predictability and listen with the goal to see the big picture and unexpected outcomes.

From this it is clear that a metacognitive awareness and understanding of self, task and strategy, in this case knowledge of personality type and listening style, may be fruitful when planning, monitoring and evaluating one's own learning activities, and leading to more effective listening.

\section{Conclusion: Making Listening Part and Parcel of Teaching and Learning}

The challenge is to make this part and parcel of course content and delivery. It is not enough to have listening tips somewhere on a website, even though this is still better than nothing. Educators should link to assessment of and training in listening style, and then use it in their course. An example may be to give assignments such as the following: "Listen to the TED presentation by So-and-So, critically evaluating his use of facts to substantiate his case. Thereafter, listen to the same presentation, listening for ways in which the speaker uses strategies to endear himself to the audience. Lastly, make a summary of the presentation, indicating how the speaker structured his presentation, but also how he used elements of surprise to keep the audience's attention."

Listening is a crucial aspect of our learning activities. Listening is, however, a neglected skill that should be highlighted and developed. This is possible within a metacognitive framework, which could guide us in two ways. The first is guiding us and teaching us how to listen properly, and the second is to teach us how to speak and lecture in ways that makes it easy to be listened to. Technological advances make it imperative that all educators, whether at contact or at ODL institutions, become aware and knowledgeable about this, and therefore we have to put Listening back into ODEL. 


\section{References}

Anderson, T. \& Dron, J. (2011). Three generations of distance education pedagogy. International review of research in open and distance learning. Vol 12(3), 80-97.

Beall, M., Gill-Rosier, J., Tate, J. \& Matten, A. (2008). State of the context: listening in education. International journal of listening, 22, 123-132.

Bodie, G. D, Worthington, D. L. \& Gearhart, C. C. (2013). The Listening Styles Profile-Revised (LSP-R): A Scale Revision and Evidence for Validity, Communication Quarterly, 61:1, 72-90.

Carver R. P., Johnson, R. L. \& Friedman, H. L. (1970). Factor analysis of the ability to comprehend time-compressed speech. (Final report for the National Institute for Health). Washington, DC: American Institute for Research.

Coakley, C., \& Wolvin, A. (1997). Listening in the educational environment. In: M.Purdy \& D. Borisoff (Eds.) Listening in everyday life: A personal and professional approach ( $2^{\text {nd }}$ ed.) (pp. 179-212). Lanham, MD: University Press of America.

Conaway, M. S. (1982). Listening: Learning tool and retention agent. In A.S. Algier \& K.W. Algier, (Eds.), Improving reading and study skills, (pp. 51-63). San Francisco: Jossey-Bass.

Durbridge, N. (1984). Media in course design, No. 9, audio cassettes. In: The role of technology in distance education. Kent: Croom Helm.

Flavell, J. H. (1976). Metacognitive aspects of problem solving. In L. B. Resnick (Ed.), The nature of intelligence (pp.231-236). Hillsdale, NJ: Erlbaum.

Flavell, J. H. (1979). Metacognition and cognitive monitoring. A new area of cognitive-development inquiry. American Psychologist 34 (10): $906-$ 911.

Gous, I. \& Roberts, J. (2013). Breaking the sound barrier: using technology to bridge the divide between lecturer and student in an ODL setting. In: R. Sims \& M. Kighoto (Eds.) Education across space and time. (35-46). Open and Distance Learning Association of Australia.

Hardiman, M. M. (2012). The Brain-Targeted Teaching Model for 21st-Century Schools. Thousand Oaks: Corwin.

Heydenrych, J. F. \& Prinsloo, P. (2010). Revisiting the five generations of distance education. Progressio 32 (1), 5-26.

http://academic.cuesta.edu/acasupp/as/206.htm

http://owll.massey.ac.nz/esol-study/esol-listening-strategies.php

http://www.csus.edu/sswd/services/studyskillsresources.html

http://www.deakin.edu.au/current-students/study-support/study-skills/handouts/ notetaking.php

http://www.educationcorner.com/listening-skills.html

http://www.educationcorner.com/study-skills.html

http://www.educationcorner.com/textbook-strategies.html

http://www.musiccog.ohio-state.edu/Huron/Talks/SMT.2002/handout.html

http://www.slideshare.net/akor0003/three-generations-of-distance-education-pedagogies. Accessed on 8 July 2013.

Imhof, M. \& Weinhard, T. (2004, April). What did you listen to in school today? Paper presented at the 25th annual convention of the International Listening Association in Ft. Myers, FL.

Imhof, M. (1998).What makes a good listener? Listening behavior in instructional settings. International Journal of Listening, 12, 81-105.

Janusik, L. A. (2002). Teaching listening. What do we know? What should we know? International Journal of Listening, 16, 5-39.

Janusik, L. A. \& Wolvin, A. D. (2002). Listening treatment it the basic communication course text. In D. Sellnow, (Ed.), Basic Communication Course Annual. Boston: American.

Janusik, L. A. \& Wolvin, A. D. (2006). 24 hours in a day. A listening update to the time studies. Paper presented at the meeting of the International Listening Association, Salem, OR.

Stauffer, J., Frost, R, \& Rybolt, W. (1983). The attention factor in recalling network televisionnews. Journal of Communication, 33(1), 29-37.

Lee, M. \& Chan, A. (2007). Reducing the effects of isolation and promoting inclusivity for distance learners through podcasting. Turkish online journal of distance education, 8(1), 85-105.

Mehrabian, A. (1981). Silent messages: Implicit communication of emotions and attitudes. Belmont, CA: Wadsworth.

Mithen, S. J. (1996). The prehistory of the mind: a search for the origins of art, religion, and science, London: Thames and Hudson Moore.

Moore, M. (1997). Theory of Transactional Distance. In D. Keegan (Ed.) (1997). Theoretical Principles of Distance Education. Abingdon: Routledge.

Moore, M. G. (2007). The Theory of Transactional Distance. In M .G. Moore (Ed.) (2007). The Handbook of Distance Education. Second Edition.Mahwah, N.J. Lawrence Erlbaum Associates. pp. 89-108.

Nichols, R. (1948). Factors accounting for differences in comprehension of material presented orally in the classroom. Unpublished doctoral dissertation, University of IOWA.

Peters, O. (1992). Some observations on dropping out in distance education. Distance Education, 13(2), 234-269.

Roberts, J. \& Gous, I. (2013) Positive discipline and positive educators: a case syudy linking cognitive style, personality types and and disciplinary style. In: L. Wood \& C.C. Wolhuter (Eds.) (2013). Criticality, creativity and connections: in pursuit of educational innovations. Potchefstroom: Platinum.

Smaldino, S. E., Russell, J. D., Heinich, R. \& Molenda, M. (2005). Instructional technology and media for learning. Upper Sadle River, NJ: Pearson Merrill Prentice Hall.

Taylor, J. C. (2001). Fifth generation distance education. Higher education series 40. June. Australia: Department of Education, Training and Youth Affairs.

Wacker, K. G. \& Hawkins, K. (1995). Curricula comparison for classes in listening. International Journal of Listening, 9, 14-28.

Watson, K. W., Barker, L. L., \& Weaver, J. B., III (1995). The listening styles profile (LSP-16): Development and validation of an instrument to assess four listening styles. International Journal of Listening, 9, 1-13.

Watson, K. W. \& Smeltzer, L. R. (1984). Barriers to listening: comparison between students and practitioners. Communication research Reports, $1,82-87$. 